\title{
Enhancing resilience during the COVID-19 pandemic: A thematic analysis and evaluation of the warr;or21 program
}

\author{
Jeff Thompson*
}

\begin{abstract}
The novel coronavirus (COVID-19) has negatively impacted the world in a variety of ways. Thousands have died, many more have fallen ill, and it continues to have a disastrous impact on the global economy. The virus has also significantly impacted people's well-being and their mental health, where the effects are expected to continue long after businesses begin to re-open. Promoting resilience and positive mental health coping strategies are, therefore, vital to assisting people as this pandemic continues and long after a sense of "normalcy" returns. This paper, a program analysis of warr;or21, a resilience program, utilizes qualitative research methods to share the insights of participants who completed the program during the COVID-19 pandemic. The warr;or21 program was designed initially to enhance resilience in law enforcement and other first responders and has since been adapted for the general public. The data reveals that, from the perspective of the participants, warr;or21 has helped many of them cope and manage positively, specifically amid the COVID-19 pandemic. Thus, the warr;or21 program has the potential to help enhance people's resilience and mental health during future adverse events as well as to be used proactively to further develop a person's overall mental health and resilience.
\end{abstract}

Key Words Grit; mental health; positive psychology; gratitude; empathy.

\section{INTRODUCTION}

The novel coronavirus (COVID-19) has negatively impacted the world in a variety of ways. As of today, May 10, 2020, according to Johns Hopkins there is a total of 279,734 deaths and 4 million cases (John Hopkins University, 2020). These numbers continue to rise. Further, the virus produced a disastrous impact on the global economy as the most affected countries are responsible for 40 percent of the global economy (Craven, Mysore, Singhal, \& Wilson, 2020). The pandemic has also significantly impacted people's well-being and mental health, with reported high rates of anxiety, depression, and distress (Coe \& Enomoto, 2020). Another report states that nearly half (45\%) of adults living in the United States say their worry and stress associated with the COVID-19 virus has negatively impacted their mental health (Panchel et al., 2020). The negative impact of COVID-19 could be due to a variety of factors, including pre-existing conditions, loss of employment, social isolation, and burnout from those still employed during the ongoing pandemic (Panchel et al., 2020).
These effects are expected to continue long after businesses begin to re-open, and the result is expected to create a behavioural health crisis (Coe \& Enomoto, 2020), with mental health concerns growing as a second curve that will need to be addressed (Ortega, 2020). Promoting resilience and positive mental health coping strategies is, therefore, vital to assisting people as this pandemic continues and long after a sense of "normalcy" returns.

This paper uses qualitative research methods to conduct an evaluation of the warr;or21 program and share insights of the participants who completed it during the pandemic. The warr;or21 program was designed to enhance resilience in law enforcement officers and other first responders and has since been adapted for the general public. The data in this report reveals that, from participants' perspectives, this program has helped many of them cope and manage positively, with many specifically mentioning the positive benefits the program had while they were in the midst of the COVID-19 pandemic. As of the date of this publication, another report, which specifically explores the perspective of first responders (from other

Correspondence to: Jeff Thompson, PhD, New York State Psychiatric Institute/Columbia University Medical Center, 1051 Riverside Drive, Room 2412, New York, NY
10032, USA. E-mail: j+2768@cumc.Columbia.edu
To cite: Thompson, J. (2020). Enhancing resilience during the COVID-19 pandemic: A thematic analysis and evaluation of the warr; or21 program. Journal of Community
Safety and Well-Being, 5(2), 51-56. https://doi.org/10.35502/jcswb.134
@ Author(s) 2020. Open Access. This work is distributed under the Creative Commons BY-NC-ND license. For commercial re-use, please contact sales@sgpublishing.ca. gPUBLISHING Published by SG Publishing Inc. CSAA Official publication of the Community Safety Knowledge Alliance. 
cohorts) who have participated in the warr;or21 program has been submitted for publication with similar findings. An additional report, which has a much larger sample size with the majority of participants being non-first responders, is near completion and also has similar findings.

\section{PROGRAM EVALUATION}

The following research question was established to guide the evaluation of the program: How did the participants perceive the warr;or21 program impacted them, specifically while participating in it during the COVID-19 pandemic?

Thematic analysis is used to address this question, reporting the insights and experiences of participants (Braun \& Clarke, 2008; Thomas, 2003). Braun and Clarke further explain that this methodology seeks to share the reality of the individual and how they perceive an experience. The analysis conducted for this paper followed the six phases suggested by Braun and Clarke: familiarization with the data, generating initial codes, searching for themes, reviewing themes, defining and naming themes, and producing the report.

Considering there are overlaps and similarities between many qualitative approaches, grounded theory practices also assisted with the analysis as the data was broken down into manageable pieces to determine the conceptual direction to be followed (Packer-Muti, 2009). The purpose, similar to thematic analysis and other qualitative methodologies, is to reveal themes that have emerged (Bloor, 1978; Bound, 2011; Creswell, 2007; Wolcott, 1990).

The data source is participant comments provided during the program, as well as the post-program survey used to evaluate the warr;or21 program. Program participation, giving feedback, and completing the post-program evaluation survey were voluntary.

The examination of the data consists of both inductive analysis, as the themes are strongly linked to the data itself, and theoretical analysis, as the construct of the warr;or21 program helped guide the analysis. An example of inductive analysis is that COVID-19 was never indicated as a prompt for reflection during the program or during the post-program survey. Instead, the participants chose to connect their program experiences with the ongoing pandemic. An example of theoretical analysis is using the program's design and key practices as a lens to gain the insight of the participants. This includes exploring statements made about the benefits of the breathing exercises, which are a core practice in the warr;or21 program.

\section{THE WARR;OR21 PROGRAM EXPLAINED}

The warr;or21 program, created by the author, is a 21-day resilience program that is conducted through the Google Classroom application and can be accessed through Google Classrooms on a variety of devices (from smartphones to computers). The program takes place over the course of 21 days, Monday through Friday, meaning participants have weekends "off." Each day during the program, participants receive an alert on their mobile devices (by allowing notifications through the app) containing a link directing them to a file that contains the day's daily practices. The daily practices, which take 10 to 15 minutes to complete, are structured around the daily key word: a quote, five minutes of controlled breathing practice, a short science-based article on the key word, a brief reflection on the key word and the article to guide them during the rest of their day, and a gratitude practice. It is suggested that all of the practices be completed in the morning, except the gratitude practice, which it is considered better to complete in the evening just before going to sleep.

\section{PARTICIPANTS}

The warr;or21 had multiple cohorts participating in the program during the COVID-19 pandemic. For this report, a purposeful sample of one cohort consisting of 46 participants was selected to conduct the program evaluation using thematic analysis. Participants in each of the cohorts voluntarily joined the program, and outreach was conducted by the author through informal networks, email lists, and through referrals from previous participants. Participants in this cohort were from Spain, the United Kingdom, and the United States, and various agencies for the first responder participants. A purposeful sample, common in qualitative research (Palinkas et al., 2015), was used to restrict the participants to one particular cohort. The cohort had just completed the program at the writing of this report, thus making them ideal to offer their knowledge and experience of the program during the COVID-19 pandemic (Creswell, 2007; Patton, 2002). A total of 16 participants completed the post-program survey: 4 males, 12 females; 10 civilians, 1 civilian in law enforcement, 4 uniformed law enforcement members, and 1 (other) first responder in the program.

\section{THEMES}

As a result of using the thematic analytical six-phase framework (Braun \& Clarke, 2008), the individual experiences that were shared by participants were grouped into the following five themes: the impact of the warr;or21 program on the individual while in the midst of the global COVID-19 pandemic, the overall design of the program, the breathing practices, the gratitude practice, and the personal benefit of participating.

\section{COVID-19 and the warr;or21 Program}

Without being solicited, numerous participants mentioned the benefits of participating in the warr;or21 program while being in the midst of the global COVID-19 pandemic. These benefits include warr;or21 providing them consistency and normalcy during a time when the pandemic had taken aspects of control away from people's everyday lives:

"Thank you for inviting me to complete this program. It has provided me with a sense of calm and normalcy in this unprecedented time."

\footnotetext{
"This course has been an amazing way to start my days during these uncertain and unstructured times."

"I am grateful for being able to take something good from these hard times. This program is definitely helping me to keep centred and enjoy simple moments."
} 
Other participants stated how the program's specific practices helped them:

"During the crazy C19, the readings, journals and breath work kept me grounded. Brought me back to centre and provided me tools to deal with some very stressful situations."

"Doing this course during COVID-19, when there is so much stress and uncertainty, has really helped me be less reactive through the breathing exercises and practice gratitude nightly through journaling."

However, other participants were more generalized about how the program assisted them:

"Truly [there was] was no better time to take on this challenge."

"This program has come at the most important time and has a deeper meaning than any of us could have ever expected."

“Thank you for these perspectives as they couldn't fall at a better time."

Certain participants explained how the benefits of the program extended to others too, both in their professional and personal lives:

"It was a pleasure to complete the 21 days during this insane time. It could not have been at a better time to help me and my family cope."

"I have been stressed and on edge worrying about my family and their health during this pandemic. This program has made me take time out of my day for myself."

Again, the comments related to COVID-19 shared by the participants both during the course and as part of the post-program were not solicited. Instead, they each chose to connect the program to something personally meaningful. The multiple statements made related to life amidst COVID-19 demonstrate how this theme emerged from inductive analysis (Braun \& Clarke, 2008; Thomas, 2003).

\section{The warr;or21 Program Design}

The warr;or21 program's design is based on numerous other resilience programs and practices (Emmons, 2010; Gillihan, 2018; Hanson, 2016; Korb, 2015; Reivich \& Shatte, 2003; Seligman, Steen, Park, \& Peterson, 2005; Siegel, 2018; Southwick \& Charney, 2018; Tabibnia \& Radecki, 2018; Wilson, 2016) and has been purposely constructed to provide participants with daily practices that are both practical and science-based. Research has also demonstrated the importance of being flexible and having various resilience practices available (Bonanno, 2013; Wu et al., 2013). Feedback from participants noted how the program's design specifically helped them, especially when asked in an open-ended manner in the survey what they liked most about the program:
“The structure. The daily themes."

"It gave a structured outline for each day."

"Each day was to the point with actionable steps."

Additional participants shared their appreciation, specifically with respect to the program's structure:

"The program was a well-structured, deeply informed step into practical mindfulness practice."

"Just thanks for pulling it all together and presenting it in a concise format."

"The structure of the program was quite helpful. The readings, questions, and comments allow for a unique self-exploration in a relatively short period of time. It pulled together many of the lessons I have learned over the years in an accessible manner and allowed for a deeper reflection each day, which we often take for granted."

Finally, the following two participants mentioned the structure of the program, specifically with the various practices connected to the daily controlled breathing:

"I liked the way it built on existing knowledge as a way to develop the learning, but also gradually built the physical skills associated with the breathing exercises while also embedding the habit of doing them."

"I loved how the program integrated starting the positive habits it talks about via the breathing and gratitude exercises. I also appreciated the many different sources it pulled from-the extra reads were great."

The controlled breathing practices are one of the core practices of the program and emerged, as previously stated, as a theme based on both inductive and theoretical analysis.

\section{Controlled Breathing Practices}

The warr; or 21 program consists of various controlled breathing practices that are part of the daily core morning routine. As previously shared, controlled breathing can help reduce anxiety and depressive symptoms, improve focus and sleep, and regulate emotions (Doll, 2016; Doria, de Vuono, Sanlorenzo, Irtelli, \& Mencacci, 2015; Greenberger \& Padesky, 2016; Kwekkeboom \& Bratzke, 2016; Pozuelos, Mead, Rueda, \& Malinowski, 2019; Siegel, 2018). Participants expressed appreciation of doing these practices:

"Enjoyed the breathing exercise. Found it to be calming, refreshing, refocus, and if sleepy will put you to sleep."

"The breathing exercises have become a beneficial ritual every evening in my home." 
Finally, the following participant connected the controlled breathing practices with the other core practice of the warr;or21 program, expressing gratitude:

"The breathing and gratitude exercises are something I definitely wish to continue even after the program is over."

The breathing practices, along with evening practice in gratitude, were included specifically due to the overwhelming research detailing their importance to resilience and positive mental health (Chu, 2016; Cunha, Pellanda, \& Reppold, 2019; Dean, 2013; Doll, 2016; Doria et al., 2015; Emmons \& McCullough, 2003; Emmons, 2010; Greenberger \& Padesky, 2016; Korb, 2015; Kwekkeboom \& Bratzke, 2016; Pozuelos et al., 2019; Siegel, 2018). Because of the importance of the breathing practices, the warr;or21 program was specifically designed to have them start the day (controlled breathing) and conclude each day (gratitude practice).

\section{Gratitude Practice}

The gratitude practice, based on the specific structure for this program, is unique; however, at the same time, it is based on numerous similar practices that the literature has stated as being beneficial to one's mental health and resilience (Chu, 2016; Cunha et al., 2019; Dean, 2013; Emmons \& McCullough, 2003; Emmons, 2010; Korb, 2015; Neff, 2015). Based on the literature, a distinct gratitude practice was developed. Each evening the participant is instructed to write in a notebook the following three things for that day: one thing that made them happy, one kind thing someone did for them, and one kind action they did for someone else.

To increase the purposeful, daily reflection, participants are asked not to repeat details they write in the journal during the 21-day course. Various gratitude practices are beneficial; however, writing down things one is grateful for has especially been shown to have benefits (Cheng, Tsui, \& Lam, 2015; Fritz, Armenta, Walsh, \& Lyubomirsky, 2019). Finally, engaging in the gratitude practice was designed to be completed close to bedtime, as this, too, has been shown to have benefits with helping people sleep (Korb, 2015; Wood, Joseph, Lloyd, \& Atkins, 2009).

Some participants specifically stated the positive impact the gratitude practice had:

"Practicing gratitude has made me a much happier person. I am no longer the angry individual that I was a couple months ago and people have taken notice [of] that."

"I have found a lot of success in writing my thoughts out. And focusing on our gratitude questions each night."

One participant associated gratitude practice with their perspective and sense of agency, focusing on what they do have control over and also appreciating certain aspects of what is happening. Hanson explains "agency" as being the cause and not the effect (Hanson, 2018). This is critical to resilience as it can counter feelings of hopelessness:
"When I work at finding gratitude, when I work at giving kindness, when I work at pausing and resetting my story - that makes me feel good and allows me to rise above what is happening around me."

Other participants stated the importance of gratitude and how they are sharing it with others:

"For myself, gratitude is the most powerful tool for wellness. Although it may seem difficult at times, it becomes very easy to implement and very easy to spread."

"I'm going to start posting my daily gratitude practice on Facebook in the evenings and challenge my friends to start one of their own."

The above comments demonstrate how gratitude emerged as a theme while evaluating the warr;or21 program. The participants' reflections are also consistent with the previously mentioned research studies that have established gratitude practices as being critical to developing and enhancing resilience.

\section{Personal Benefits}

The warr;or21 program is presented to participants as part of the personal journey to find personal well-being and mental health. The program emphasizes that, regardless of one's employment or tasks in life, it is necessary to look after oneself. The participants are reminded that this is not selfish; it is smart. Considering the program was created for law enforcement and first responders, this is critically important, especially during the COVID-19 pandemic, as psychological trauma has been described as the next crisis for front-line workers (Mock, 2020).

This theme of the program providing a personal benefit to participants emerged through both inductive analysis and theoretical analysis. The participants shared the following comments freely, while also replying specifically to a postprogram survey question asking them to describe what the program meant to them.

Here, some of the participants shared their gratefulness by realizing the personal benefits the program had for them:

"The program gave me confidence and the tools to really start depending on myself to take care of myself."

"By sitting down to review materials, I feel it is the only time in my day to focus on something for me."

"A tool to explore your mind, learn about yourself and find new ways to build mental resilience."

"Thank you for a great experience and the wealth of mind-blowing information. Between the videos and articles, I really learned a lot."

Although these reflections do not specifically mention COVID-19, the following two participants reflected on the timing of the program: 
"I have learned (from the past 19 days in fact) that being mindful for yourself is so more important now."

"I think the program is super. I took it at a time when I did need it the most."

The following participants detail how the third pillar of resilience in the warr;or21 program, which emphasizes having a purpose that benefits the self while also supports others, impacted them:

"It has also forced me to 'pause' during my day to make time for myself, which helps me better serve others."

"I sincerely believe that this program helped me to deal with stressors in a more thoughtful and meaningful way, and strengthening my resilience allowed me to be there for others."

The program also provided participants an opportunity to motivate themselves further to continue improving their resilience and mental health after the program had finished:

"I thought this program was a great catalyst and motivator in helping me pursue more resilience in my life and helping me to find a fulfilling career path."

The above participants' statements, about the personal benefits they gained by participating in the program, demonstrate how this program had a significant impact on them.

\section{CONCLUSION}

Programs like warr;or21 and other resilience programs cannot be limited to quantitative statistical analysis. Resilience involves a person's perspective. When measuring terms like success and impact, it is only through a qualitative methodology that the information in this report can be gathered, address the guiding question, and allow the five themes to emerge: the impact warr;or21 had on participants during the COVID-19 pandemic, the design of the program, the controlled breathing exercise, the gratitude practice, and the personal benefits of participating in the program. We acknowledge that this report uses one type of analysis to examine the impact of the warr;or21 program, and thus is limiting in numerous ways.

To conduct a more robust program evaluation, further research is needed to determine the program's impact. This research includes evaluation during the program, the immediate effects after it is concluded, and also exploring the long-term impact. This can include both qualitative and quantitative methodologies.

Qualitatively, similar strategies can be further expanded and used with participants to gauge their perspectives prior to participating, throughout the program, immediately upon completion, and after a set time has passed since finishing warr;or21.

The sample size was small and consistent with qualitative methodologies which does not limit the findings given the scope and purpose of this report. However, future studies can complement these findings and enhance them by using quantitative methodologies. A larger sample size and a sophisticated strategy involving quantitative analysis can expand on the individual experiences and themes that have emerged in this report to identify significant relationships from the data (including comparisons between subgroups such as first responders and civilians, males and females, geographic location, and other key areas).

This analysis has shown that, based on the feedback from participants in the program, warr;or21 offers individuals an opportunity to enhance their resilience and mental health, especially during the tumultuous COVID-19 period, as many continue to be impacted by this global pandemic. The warr;or21 program also has the potential to help people enhance their resilience and mental health during future, adverse events. Finally, and importantly, the warr;or21 program should also be considered to proactively develop a person's overall mental health further. As the program continues to expand with participants, so too must its evaluation and scientific analysis to measure the impact it has on participants.

\section{CONFLICT OF INTEREST DISCLOSURES}

The authors have no conflicts of interest to declare.

\section{AUTHOR AFFILIATIONS}

*Adjunct Associate Research Scientist, Molecular Imaging and Neuropathology Division, New York State Psychiatric Institute/ Columbia University Medical Center, New York, NY, USA; Adjunct Instructor, Institute for Conflict Management, Lipscomb University, Nashville, TN, USA.

\section{REFERENCES}

Bloor, M. (1978). On the analysis of observational data: A discussion of the worth and uses of inductive techniques and respondent validation. Sociology, 12(3), 545-552. doi: 10.1177/003803857801200307

Bonanno, G. A. (2013). Meaning making, adversity, and regulatory flexibility. Memory, 21(1), 150-156. doi: 10.1080\%2F09658211.2012.745572

Bound, M. (2011). Qualitative method of research: Phenomenological method. Retrieved from: http://www.academia.edu/1526812/ Qualitative_Research_Phenomenological_Method

Braun, V., \& Clarke, V. (2008), Using thematic analysis in psychology. Qualitative Research in Psychology, 3(2), 77-101. Retrieved from: https://core.ac.uk/download/pdf/1347976.pdf

Cheng, S. T., Tsui, P. K., \& Lam, J. (2015). Improving mental health in health care practitioners: Randomized controlled trial of a gratitude intervention. Journal of Counseling and Clinical Psychology, 83(1), 177-186. doi: 10.1002/gps.1314

Chu, C. (2016, November 25). Bulletproof mind: 6 secrets of mental toughness from the Navy SEALs. Observer.com. Retrieved from: https://observer.com/2016/11/bulletproof-mind-6-secrets-of-mentaltoughness-from-the-navy-seals/

Coe, E. H., \& Enomoto, K. (2020, April 2). Returning to resilience: The impact of COVID-19 on mental health and substance use. Mckinsey. Retrieved from: https://www.mckinsey.com/industries/healthcaresystems-and-services/our-insights/returning-to-resilience-the-impactof-covid-19-on-behavioral-health

Craven, M., Mysore, M., Singhal, S., \& Wilson, M. (2020, April 13). COVID-19: Briefing note. McKinsey. https://www.mckinsey.com/ business-functions/risk/our-insights/covid-19-implications-for-business

Creswell, J. W. (2007). Qualitative inquiry and research design: Choosing among five approaches (2nd ed.). Thousand Oaks, CA: Sage Publications, Inc. 
Cunha, L. F., Pellanda, L. C., \& Reppold, C. T. (2019). Positive psychology and gratitude interventions: A randomized clinical trial. Frontiers in Psychology, 10, 584. doi: 10.3389\%2Ffpsyg.2019.00584

Dean, J. (2013). Making habits, breaking habits: Why we do things, why we don't, and how to make any chance stick. Philadelphia, PA: De Capo Press.

Doll, A. (2016). Mindful attention to breath regulates emotions via increased amygdala-prefrontal cortex connectivity. Neurolmage, 134, 305-313.

Doria, S., de Vuono, A., Sanlorenzo, R., Irtelli, F., \& Mencacci, C. (2015). Anti-anxiety efficacy of Sudarshan Kriya Yoga in general anxiety disorder: A multicomponent, yoga-based, breath intervention program for patients suffering from generalized anxiety disorder with or without comorbidities. Journal of Affective Disorders, 184, 310-317.

Emmons, R. A., \& McCullough, M. E. (2003). Counting blessings versus burdens: Experimental studies of gratitude and subjective well-being. Journal of Personality and Social Psychology, 84, 377-389. Retrieved from: https://greatergood.berkeley.edu/images/application_up loads/Emmons-CountingBlessings.pdf

Emmons, R. (2010, November 17). 10 ways to become more grateful. Greater Good Magazine. Retrieved from: https://greatergood. berkeley.edu/article/item/ten_ways_to_become_more_gratefull

Fritz, M., Armenta, C. N., Walsh, L. C., \& Lyubomirsky, S. (2019). Gratitude facilitates healthy eating behavior in adolescents and young adults. Journal of Experimental Social Psychology 81, 4-14.

Gillihan, S. (2018). Cognitive behavioral therapy made simple: 10 strategies for managing anxiety, depression, anger, panic, and worry. New York, NY: Althea Press.

Greenberger, D., \& Padesky, C. A. (2016). Mind over mood: Change how you feel by changing the way you think (2nd ed.). New York, NY: The Guilford Press.

Hanson, R. (2016). Hardwiring happiness: The new brain science of contentment, calm, and confidence. New York, NY: Harmony Books.

Hanson, R. (2018). Resilient: 12 tools for transforming everyday experiences into lasting happiness. New York, NY: Harmony Books.

Johns Hopkins University Hub staff report. (2020, April 16). COVID-19'S historic economic impact, in the U.S. and abroad. Johns Hopkins University. Retrieved from: https://hub.jhu.edu/2020/04/16/ coronavirus-impact-on-european-american-economies/

Korb, A. (2015). The upward spiral: Using neuroscience to reverse the course of depression, one small change at a time. Oakland, CA: New Harbinger.

Kwekkeboom, K., \& Bratzke, L. (2016). A systematic review of relaxation, meditation, and guided imagery strategies for symptom management in heart failure. Journal of Cardiovascular Nursing, 37(5), 457-468.

Mock, J. (2020, April 28). Psychological trauma is the next crisis for coronavirus health workers. Scientific American. Retrieved from: https://www.scientificamerican.com/article/psychological-traumais-the-next-crisis-for-coronavirus-health-workers/

Neff, K. (2015). Self-compassion. New York, NY: William Morrow.

Ortega, R. P. (2020, April 22). Health care workers seek to flatten COVID-19's 'second curve'-their rising mental anguish. Science Magazine. Retrieved from: https://www.sciencemag.org/news/2020/04/ health-care-workers-seek-flatten-covid-19-s-second-curve-their-risingmental-anguish
Packer-Muti, B. (2009). A review of Corbin and Strauss' basics of qualitative research: Techniques and procedures for developing grounded theory. The Qualitative Report, 12(2), 140-143. Retrieved from https://nsuworks.nova.edu/tar/voll4/iss2/12

Palinkas, L. A., Horwitz, S. M., Green, C. A., Wisdom, J. P., Duan, N., \& Hoagwood, K. (2015). Purposeful sampling for qualitative data collection and analysis in mixed method implementation research. Administration and Policy in Mental Health, 42(5), 533-544. doi: 10.1007/s10488-013-0528-y

Panchel, N., Kamal, R., Orgera, K., Cox, C., Garfield, R., Hamel, L., Munana, C., \& Chidambaram, P. (2020, April 21). The implications of COVID-19 for mental health and substance use. Kaiser Family Foundation. https://www.kff.org/health-reform/issue-brief/ the-implications-of-covid-19-for-mental-health-and-substance-use/

Patton, M. Q. (2002). Qualitative research and evaluation methods (3rd ed.). Thousand Oaks, CA: Sage Publications, Inc.

Pozuelos, J. P., Mead, B. R., Rueda, M. R., \& Malinowski, P. (2019). Shortterm mindful breath awareness training improves inhibitory control and response monitoring. Progress in Brain Research, 6, 137-163. doi: 10.1016/bs.pbr.2018.10.019.

Reivich, K., \& Shatte, A. (2003). The resilience factor: 7 keys to finding your inner strength and overcoming life's hurdles. New York, NY: Harmony Books.

Seligman, M. E. P., Steen, T. A., Park, N., \& Peterson, C. (2005). Positive psychology progress: Empirical validation of interventions. American Psychologist, 6015), 410-421. doi: 10.1037/0003-066X.60.5.410

Siegel, D. (2018). Aware: The science and practice of presencethe groundbreaking meditation practice. New York, NY: TarcherPerigee.

Southwick, S. M., \& Charney, D. S. (2018). Resilience: The science of mastering life's greatest challenges. Cambridge, UK: Cambridge University.

Tabibnia, G., \& Radecki, D. (2018). Resilience training that can change the brain. Consulting Psychology Journal: Practice and Research, 70(1), 59-88. doi: 10.1037/cpb0000110

Thomas, D. R. (2003). A general inductive approach for qualitative data analysis. Retrieved from: http://www.frankumstein.com/PDF/Psychology/Inductive\%20Content\%20Analysis.pdf

Wilson, J. T. (2016). Brightening the mind: The impact of practicing gratitude on focus and resilience in learning. Journal of the Scholarship of Teaching and Learning, 16(4), 1-13. Retrieved from: files.eric. ed.gov/fulltext/EJ1112485.pdf

Wolcott, H. F. (1990). On seeking-and rejecting-validity in qualitative research. In E. W. Eisner \& A. Peshkin (Eds.), Qualitative inquiry in education: The continuing debate (pp. 121-152). New York: Teachers College Press.

Wood, A. M., Joseph, S., Lloyd, J., \& Atkins, S. (2009). Gratitude influences sleep through the mechanism of pre-sleep cognitions. Journal of Psychosomatic Research, 66, 43-48. doi: 10.1016/i. jpsychores.2008.09.002

Wu, G., Feder, A., Cohen, H., Kim, J. J., Calderon, S., Charney, D. S., \& Mathe, A. (2013). Understanding resilience. Frontiers in Behavioral Neuroscience, 7(10). doi: 10.3389/fnbeh.2013.00010 